\title{
TASTY ROADS TO FLAVOUR
}

\author{
AXEL BARCELÓ ASPEITIA \\ https:/ / orcid.org/0000-0002-0693-5910 \\ UNAM - Instituto de Investigaciones Filosóficas \\ Coyoacan - Ciudad de México \\ México \\ abarcelo@filosoficas.unam.mx
}

\begin{abstract}
Article info
CDD: 401

\section{Keywords \\ Reference \\ Relativism \\ Flavour \\ Context Sensitivity}

Aesthetic Properties
\end{abstract}

Received: 27.07.2020; Accepted: 15.08.2020

https://doi.org/10.1590/0100-6045.2020.V43N4.AB

\begin{abstract}
The goal of this brief note is to offer a generalisation of Gómez-Torrente argumentative strategy against perspectivism, which he has developed as a defence of color realism in (2016) and (2019) and then apply it to evaluative language. In particular, I want to defend the thesis that at least some aesthetic predicates can have non-evaluative reference. As an example, I will work with the predicate "tasty" (and its antonym "disgusting") to argue that it some times refers to a non-subjective non-evaluative property, flavour, which is more fundamental that the relational property of being tasty to someone. In other words, some times, when we say of something that it is tasty, we are not saying how it tastes to us or whether we like it, but just how it tastes period.
\end{abstract}

The goal of this brief note is to offer a generalisation of Gómez Torrente argumentative strategy against perspectivism, which he has developed as a defence of color realism in (2016) and (2019) and then apply it to aesthetic 
language. In particular, I want to defend the thesis that at least some aesthetic predicates can have non-perspectival reference. As an example, I will work with the predicate "tasty" (and its antonym "disgusting") to argue that it some times refers to a non-subjective non-evaluative property, flavour, which is more fundamental that the relational property of being tasty to someone. In other words, some times, when we say of something that it is tasty, we are not saying how it tastes to us or whether we like it, but just how it tastes period.

The structure is as follows. I will start by introducing the general phenomenon of using subjective, perspectival or context-dependent language for referring to objective, nonperspectival or context-invariant properties. I will present first the abstract general account and then illustrate it with the indexical expressions "left" and "right" These are perspectival expressions we usually use to talk about a nonperspectival property: an object's spatial location. Then, I will develop Gómez-Torrente's insights into a pair of general criteria, which I will call contextual sensibility and stability, that might serve as test for this phenomenon. Finally, I will use the test to argue that we have good reasons to think that "tasty" fits the resulting characterisation and thus that it is a subjective evaluative expression we sometimes use to talk about a non-perspectival non-evaluative property: flavour. This results recovers what I take to be a commonsensical intuition regarding tastiness and flavour: that two things cannot be considered (in the same context, by the same taster) one tasty, the other not, and yet both taste the same. 


\section{CONTEXT-SENSITIVE EXPRESSIONS THAT DO NOT EXPRESS CONTEXT-SENSITIVE PROPERTIES}

Here is a common phenomenon: Whenever there are predicates P1 and P2 (and sometimes P3, P4, etc.) such that there is a (determinable) property $\mathrm{P}$, at least one object $\mathrm{X}$ and a pair of contexts $\mathrm{C} 1$ and $\mathrm{C} 2$ such that:

Part I: Sensibility

1. In context $\mathrm{C} 1$, a (literal, assertoric, nondescriptive, de re, etc.) utterance of " $\mathrm{X}$ is $\mathrm{P} 1$ " is true. 2. In context $\mathrm{C} 2$, a (literal, assertoric, nondescriptive, de re, etc.) utterance of "X is $\mathrm{P} 2$ " is true.

c. P1 and P2 are incompatible predicates (nothing can be both $\mathrm{P} 1$ and $\mathrm{P} 2$ at the same time).

Part II: Stability

4. Both " $\mathrm{X}$ is P1" and " $\mathrm{X}$ is P2" are adequate answers to the question "How $\mathrm{P}$ is X?" (or similar: "What is the P of X?", "Which P is X?", "How does $\mathrm{X} P$ ?", etc. given that $\mathrm{P}$ is a determinable property). 5. Yet, changing $\mathrm{X}$ from $\mathrm{C} 1$ to $\mathrm{C} 2$ does not change how $\mathrm{P} X$ is. ${ }^{1}$

Then, P1 and P2 (which are sensitive to contextual differences between $\mathrm{C} 1$ and $\mathrm{C} 2$ ) refer to (determinate values

1. An equivalent way of testing for stability:

5'. For every $\mathrm{X}$ and $\mathrm{Y}$, if $\mathrm{X}$ and $\mathrm{Y}$ are of the same $\mathrm{P}$ (i.e., the $\mathrm{P}$ of $\mathrm{X}=$ the $\mathrm{P}$ of $\mathrm{Y}$ ), then $\mathrm{X}$ is $\mathrm{P} 1$ iff $\mathrm{Y}$ is $\mathrm{P} 1$, and $\mathrm{X}$ is $\mathrm{P} 2$ iff $\mathrm{X}$ is $\mathrm{P} 2$. I have decided to not be very strict in maintaining the use/mention distinction in order to keep the presentation as simple as possible without incurring in too much risk of confusion. 
of determinable) property $\mathrm{P}$ (which is not sensitive to those contextual differences).

Without a doubt, the best known examples of this phenomenon are indexicals, such as the predicates "left" and "right". Just like any other indexicals, they are context sensitive. Right now, the window of my studio is to the right, but if I turn around, it would be to the left. Being to the right and being to the left are incompatible. Yet, they are also contextually stable regarding the object's location, since both are acceptable answers to the question "Where is the window?', yet my turning around does not change where the window is. It is not the window that moves, it is me and, with me, those aspects of the context that the expressions "left" and "right" are sensitive to. Thus, even though being to the left of Axel Barceló Aspeitia at 2:06 pm on Saturday the 7th of January 2012 may well be a genuine relational property of the window, the window having that property is not what makes true the proposition expressed by me when I (literally, nondescriptively, de re, etc.) assert that "the window is to the left" to describe its location.

Notice that the claim is not that "left" and "right" always refer to location. That would be false. We use indexical expressions with other sorts of referents as well (Ezcurdia 2014). For example, when describing the condition of a person with unilateral neglect we say that she is unable to process sensory signals from objects on her left side, it is not the location of those objects that makes them imperceptible, but the way they are spatially related to her. Instead, the claim is that once we have location, we can build up the referents for the other uses of these adjectives from the relevant objects' locations and their spatial relations. Thus, the relational fact that the window is to my right is metaphysically derived, at least in part, from the more fundamental fact that the window is located where it is. 
Besides indexicals and color adjectives, other examples of predicates of this sort are gradual antonyms like "tall" and "short" (for height): "Tall" and "short" are context-sensitive ways of talking about the non-perspectival property height. In standard contexts, when we say that someone is tall, the relevant property we refer to is just being taller that $x$, for some contextually determined value $x$. Yet this contextual determination need not be part of the property itself, it might just be involved in the way we fix the relevant property. For example, sometimes the threshold of how tall someone has to be in order to be called "tall" will be determined by a comparison group of contextually salient peers. For instance, if I say that Karen is tall in the context of ordering uniforms for our battalion, the salient group might be other soldiers. In that case, however, the adjective "tall" need not refer to the relational property of being taller than your typical soldier or anything similar, but just to the range of heights greater than that of your typical soldier. In consequence, in order to make sense of the semantics of "tall" and "short" we do not need to postulate such relational properties as being tall or short. Instead "tall" and "short" can be easily modelled as contextsensitive expressions we use to talk about height, i.e., about how tall people are.

\section{GÓMEZ-TORRENTE ON COLOR}

In (2019) and (2016), Gómez-Torrente has adroitly used this robust fact to offer a counter-argument against color subjectivism, and in particular against to those who appeal to the existing enormous variation in colour reports to defend the claim that colours are subjective secondary properties. This is how Gómez-Torrente himself presents his target: 
There is much evidence indicating that different apparently normal people perceive the same colored thing via qualitatively different experiences. This leads them to make what appear to be incompatible color judgments, judgments which, given that the different people in question seem perfectly normal, would nevertheless appear to be equally faultless. These facts have provoked [among others, a set of] somewhat ad hoc and linguistically improbable views on which color judgments (and judgments about sounds, heat, etc.) involve reference to subjective, secondary qualities. (Gómez-Torrente 2019: 19)

Against these views, Gómez-Torrente urges us to recognise that context sensitive predicates might still refer to non-perspectival properties of objects, i.e., that even if these expressions shift extension in relation to some contextual or subjective feature, the property or entity that they refer to might nevertheless not be metaphysically constituted by or in relation to that feature. As straightforward examples, he offers shapes and colours to be objective features of reality that we nevertheless refer to by using context sensitive expressions like "yellow" or "square". Unfortunately, he does not say much more about when contextual sensitivity denotes genuine metaphysical dependence and when not. To fill this void, I have added the condition of stability above. The main idea is that, for example, even though we can use expressions like "right" or "left" to refer to relational spatial properties of objects, the fact that we also use them to talk about their location does not make location a relational property. It is not hard to see that shape and colour predicates are stable in this sense (further details are found in chapter 6 of Gómez-Torrente 2019). Thus, my claim is 
that expressions that show both contextual sensitivity and stability are expressions that exploit contextual or subjective features to talk about properties and objects that do not actually depend or are constituted by those features."Left" and "right" do not usually refer to perspectival properties; instead, they are context-sensitive expressions we commonly use to talk about an object's spatial location. In my example above, the window's location is one of its objective properties, and it is its being located where it actually is that makes the propositions expressed by "The window is to the right" in C1 and "The window is to the left" in C2 true, not its being spatially related in some particular way to the utterer in each context. Consequently, the truth of these assertions is independent of the location of the utterer. Finally, GómezTorrente (2016) also makes the point that, even while the predicates $\mathrm{P} 1, \mathrm{P} 2, \mathrm{P} 3$, etc. may be said to be more or less vague or precise, etc., these features do not belong to the properties themselves. Colours, heights, shapes, locations, etc. are neither coarse nor fine grained, it is the way we talk about them which might be more or less fine or coarse grained.

A couple of important ways in which my way of cashing out the stability condition differs from what GómezTorrente does in his discussion of color adjectives is that, first, he uses only examples that show a very specific and well-behaved sort of contextual sensibility. His examples are gradual adjectives where the relevant contextual variation affects only the threshold value of the positive form of the adjective along the relevant dimension. Two non-deficient observers might disagree whether an object is yellow or not, for example, only if they (implicitly) disagree as to how yellow something must be in order to be yellow, most likely because of "a number of physiological factors resulting in minute interpersonal differences in the absorption curves of cones" (Gómez-Torrente 2019: 242) This allows Gómez- 
Torrente to bolster his anti-perspectival case with other considerations about color perception that also point towards colour being non-perspectival. However, these consideration are not part of his linguistic argument, but extra arguments that provide further support to the antiperspectival thesis. Thus, they are not essential to the validity of the linguistic argument. My goal here is to display the logical structure of the linguistic anti-perspectival argument in all its generality and thus I have chosen to give a more neutral formulation that makes no mention to gradability or thresholds. I have also chosen to illustrate it with two examples that are both very different from GómezTorrente's and also substantially less controversial in the first case - indexicals, and substantially more controversial in the second case - predicates of taste.

The second noticeable difference is that he formulates his stability condition in terms of the context sensitive adjectives P1 and P2 themselves, instead of the determinable property P, as I do (Gómez-Torrente 2019: 242). For me, for an adjective to be stable, it is sufficient that changing the object $\mathrm{X}$ from one context $\mathrm{C} 1$ to another $\mathrm{C} 2$ does not change how $\mathrm{P} \mathrm{X}$ is; for him, in contrast, it is necessary that changing $\mathrm{X}$ from $\mathrm{C} 1$ to $\mathrm{C} 2$ does not change whether $\mathrm{X}$ is $\mathrm{P}$ or not, and while this later condition might be satisfied in the case of color $^{2}$ - moving a yellow object from the shade into the light, for example, will not change its being yellow -, it is clear that it won't work for "left" and "right" - when I turn around, the window is no longer to my right, but my left, even if it remains in the same place as before. However, it is clear that indexicals are paradigmatic examples of context-sensitive expressions that nevertheless are usually used to refer to stable properties, thus we need a condition of stability that is

2. And for adjectives of taste like "tasty" and "disgusting" actually, as we will see soon.

Manuscrito - Rev. Int. Fil. Campinas, v. 43, n. 4, pp. 01-12, Oct.-Dec. 2020. 
broad enough to fit indexicals like "left" and "right". Hence, my decision to appeal to the determinable property instead of the context sensitive expressions themselves.

\section{AESTHETIC REALISM}

What I want to argue now is that the same phenomenon arises in the case of predicates like "tasty" and "disgusting" when used to talk about flavour: they are both context sensitive and stable, and thus we must conclude that, at least in such occasions of use, their referents are flavours, instead of the perspectival properties tastiness and disgustingness.

\section{Part I: Sensitivity}

There seem to be contexts C1 and C2 where

1. In context $\mathrm{C} 1$, a (literal, assertoric, non-descriptive, de re, etc.) utterance of " $\mathrm{X}$ is tasty" is true.

2. In context $\mathrm{C} 2$, a (literal, assertoric, non-descriptive, de re, etc.) utterance of " $\mathrm{X}$ is disgusting" is true.

3. Tasty and disgusting are incompatible predicates (nothing can be both tasty and disgusting at the same time).

Part II: Stability

4. Both "X is tasty" and " $\mathrm{X}$ is disgusting" are adequate answers to the question "How does X taste?"

5. Yet changing $\mathrm{X}$ from $\mathrm{C} 1$ to $\mathrm{C} 2$ does not change how X tastes. ${ }^{3}$

3. Furthermore, for every $\mathrm{X}$ and $\mathrm{Y}$, if $\mathrm{X}$ and $\mathrm{Y}$ taste the same, then $\mathrm{X}$ is tasty (in a given context $\mathrm{C}$ ) iff $\mathrm{Y}$ is tasty (in the same context 
Notice that to say that "tasty" and "disgusting" are context sensitive is nothing but the anti-realist intuition that the same stuff can be tasty to some, but not to others, or to the same person in different moments and/or circumstances. In contrast, stability is nothing but the intuition that, in absence of conflicting top-down expectations, whenever one finds something tasty, if, instead of that thing, one had tasted something else that tasted the same, one would have found it tasty as well. This is analogous to the fact that whenever one finds something to one's left, if instead of that thing, one had found something else in that very same location, it would have also been to one's left. Accordingly, my proposal aims to bring both intuitions together in a realist account analogous to Gómez-Torrente's account of colour.

If I am right, the sensibility and stability of adjectives like "tasty" and "disgusting" means that they do not always refer to the perspectival properties tastiness and disgustingness, but instead are sometimes used as context-relative ways of talking about how stuff tastes, and not whether we like such stuff or not. Whether we find some flavours tasty or disgusting is just a subjective feature we exploit to fix the range of flavours that we refer to in our use of "tasty" or "disgusting". This does not make the flavours we ascribe to objects when we say they are tasty or disgusting evaluative or perspectival. The evaluative element is meaningful for reference fixing but does not make it to the referred property. Furthermore, different uses of the adjective "tasty" may pick different properties - different flavours - in different contexts, by different users. There is no such thing as the flavour that every thing we might truly call "tasty" in some context has. When I say that I find smoky alcoholic

C), and $\mathrm{X}$ is disgusting (in a given context $\mathrm{C}$ ) iff $\mathrm{X}$ is disgusting (in the same context $\mathrm{C}$ ).

Manuscrito - Rev. Int. Fil. Campinas, v. 43, n. 4, pp. 01-12, Oct.-Dec. 2020. 
beverages tasty, I do not mean to say that smoky alcoholic beverages have the flavour tasty (to me); instead I mean to say that the flavour of smoky alcoholic beverages is tasty (to me). In other words, tasty (to me) is not a flavour, but a way of talking of flavours that I enjoy like that of smoky alcoholic beverages. On this metaphysical account, non-perspectival tastes are more fundamental than the relational properties of being tasty to someone or other. Just as the relational fact that the window is to my right is metaphysically derived, at least in part, from the more fundamental fact that the window is located where it is, a place that so happens to be currently to my right, so the relational fact that I like the flavour of smoky alcoholic beverages is derived from the more fundamental fact that smoky alcoholic beverages taste the way they do, a way that I also happen to like. This is nothing but the metaphysical truism that people find food tasty or not depending on how it tastes and not vice versa.

In response to my realist argument, the subjectivist might still want to argue that reducing tastiness to flavour does no good to the realist, since both are subjective after all: flavour is nothing but how stuff tastes, and of course, without someone to taste stuff, stuff would not taste at all. I find this way of conceiving of flavour wrongheaded, for it mistakes what is perceived with how it is perceived. Flavour just does not pop into existence when it is tasted, i.e.. when it is perceived. Instead, to taste is just to perceive flavour. Yet, I could easily concede that flavour exists only in relation to a tasting subject without having to accept that variations in judgments of tastiness entail corresponding variation in reference. In other words, whether flavours exist independently of tasters is orthogonal to the question of whether flavours metaphysically depend on standards of taste. Otherwise, it would be hard to make sense of the idea that the same flavour can be appealing to some, but disgusting to others - as when I say that some people like 
the flavour of oak in wine, even though others people find it repulsive. Presumably, it implies that any wine that tastes like oak is appealing to some, but disgusting to others. If flavour shifted with standards of taste, the above assertion would be nonsense.

It is finally worth asking what other aesthetic predicates are also shifty and stable, and so can de said to have nonperspectival reference? I am not sure. Probably a whole bunch. Consider "salty": On the one hand, it is a contextsensitive adjective. The same dish can be salty for one palate, and not salty for another. It is also stable, since the answer "it is salty" is appropriate to the question "how does it taste", and yet when tasted by different palates, a single dish does not change its flavour. The same for "handsome": it is as shifty as "tasty" or "salty", and it seems to be as stable as well, because for any handsome subject, anybody that looks the same would also be considered handsome.

\section{REFERENCES}

Ezcurdia, Maite (2014) Los indéxicos y la semántica de Kaplan, Ciudad de México: Instituto de Investigaciones Filosóficas, UNAM.

Gómez-Torrente, Mario (2019) Roads to Reference. An Essay on Reference Fixing in Natural Language, Oxford University Press, Oxford.

(2016) "Perceptual Variation, Color Language, and Reference Fixing. An Objectivist Account", Noûs, vol. 50 (no. 1), pp. 3-40.

$(\mathrm{cc}) \mathrm{EY}$ 